\title{
Factors affecting neurological outcome in traumatic conus medullaris and cauda equina injuries
}

\author{
Stephen P. Kingwell, M.D., F.R.C.S.C., ${ }^{1}$ Armin Curt, M.D., F.R.C.P.C., ${ }^{2}$ and Marcel F. \\ DVORAK, M.D., F.R.C.S.C. ${ }^{1}$ \\ ${ }^{1}$ Combined Neurosurgical and Orthopaedic Spine Program, Department of Orthopaedics; and ${ }^{2}$ Division of \\ Neurology, University of British Columbia, Vancouver, British Columbia, Canada
}

\begin{abstract}
The purpose of this review was to describe the relevant factors that influence neurological outcomes in patients who sustain traumatic conus medullaris injuries (CMIs) and cauda equina injuries (CEIs). Despite the propensity for spinal trauma to affect the thoracolumbar spine, few studies have adequately characterized the outcomes of CMIs and CEIs. Typically the level of neural axis injury is inferred from the spinal level of injury or the presenting neurological picture because no study from the spinal literature has specifically evaluated the location of the conus medullaris with respect to the level of greatest canal compromise. Furthermore, the conus medullaris is known to have a small but important variable location based on the spinal level. Patients with a CMI will typically present with variable lowerextremity weakness, absent lower-limb reflexes, and saddle anesthesia. The development of a mixed upper motor neuron and lower motor neuron syndrome may occur in patients with CMIs, whereas a CEI is a pure lower motor neuron injury. Many treatment options exist and should be individualized. Posterior decompression and stabilization offers at least equivalent neurological outcomes as nonoperative or anterior approaches and has the additional benefits of surgeon familiarity, shorter hospital stays, earlier rehabilitation, and ease of nursing care. Overall, CEIs and CMIs have similar outcomes, which include ambulatory motor function and a variable persistence of bowel, bladder, and potentially sexual dysfunctions. (DOI: 10.3171/FOC.2008.25.11.E7)
\end{abstract}

\section{KeY Words - cauda equina injury neurological outcome $\quad$ trauma}

- conus medullaris injury •
$\mathrm{T}$ HE neurological structures affected in traumatic CMI and CEI differ significantly from those structures injured in cervical and thoracic SCIs. As such, the management of these injuries and the analysis of their outcomes must accommodate these unique features. Despite the breadth of literature concerning thoracic and lumbar spinal cord trauma, few attempts have been made to specifically address the unique prognostic and therapeutic aspects of CMI and CEI. Compounding any attempts to accurately characterize the outcomes of these injuries, it is often assumed that the conus medullaris terminates at L1-2 despite its known variable location. . $^{34,51,54}$ Most spinal trauma occurs at the thoracolumbar junction where the rigid thoracic spine transitions to the more flexible lumbar spine. ${ }^{18,23,38}$ Because the thoracolumbar spine is also the location where the distal spinal cord or epiconus, conus medullaris, and cauda equina are proximate, management decisions and prognostication should

\footnotetext{
Abbreviations used in this paper: ASIA = American Spinal Injury Association; BCR = bulbocavernosus reflex; CEI = cauda equina injury; $\mathrm{CMI}=$ conus medullaris injury; $\mathrm{EMG}$ = electromyography; $\mathrm{SCI}=$ spinal cord injury.
}

consider the unique variation in the neuroanatomical structures injured.

\section{Neuroanatomy}

There can be significant ambiguity when describing CMI and CEI. This stems from a lack of differentiation of the spinal column level; the level of the vertebra from the neurological level; and the segment of the spinal cord containing a specific alpha motor neuron and the concomitant dorsal and ventral nerve roots of that neurological segment. Unlike the cervical and the majority of the thoracic spine where the spinal column level and the neurological segment are in proximity, in the thoracolumbar region there is profound disparity between the L-5 vertebra and the segment of the spinal cord from which the L-5 dorsal and ventral roots originate.

The conus medullaris is morphologically an intumescence (analogous to the cervical cord level) of the caudal spinal cord and represents a transition from the central to the peripheral nervous system (Fig. 1). ${ }^{26}$ No clear anatomical landmark defines the rostral extent of the conus medullaris. In a cadaveric study, Wall and colleagues ${ }^{59}$ 


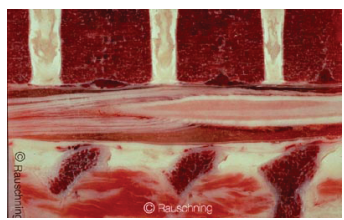

FIG. 1. Sagittal cross-section of the conus medullaris, cauda equina, and lower thoracic spinal cord.

have evaluated the neuroanatomy at the level of the distal spinal cord and conus medullaris. At the T12-L1 disc space, the spinal cord began to taper and the L1-5 nerve roots formed a peripheral rim. Only $10-15 \%$ of the spinal cord remained uncovered by nerve roots at this level. Caudally, at the L1-2 disc space, the lumbar nerve roots were oriented from lateral to medial (L-2 most lateral and L-5 most medial), and the dorsal and ventral roots had come together. At this same level, the ventral and dorsal sacral roots remained separate and the caudal sacral roots encircled the terminal cord. Kesler and associates ${ }^{34}$ have reviewed whole-spine MR images obtained in 100 children (average age 7.5 years) and found that the conus medullaris terminated between the lower third of $\mathrm{T}-12$ and the middle third of $\mathrm{L}-2$ in all children. The most common level was the lower third of L-1. Based on their review of 7 published series, the most common location for the termination of the conus medullaris was the L1-2 disc space, and the $95 \%$ confidence interval was from the T12-L1 disc space to the middle third of L-2. The range included the T11-12 disc space to the L-4 vertebra. Thus, across several spinal vertebral motion segments there exists a variety of neurological structures including the lower thoracic spinal cord or epiconus, the conus medullaris, and the cauda equina. Furthermore, the precise location of these neurological structures in relation to their specific spinal vertebral level is remarkably variable. ${ }^{34,51,54}$ The very practical impact of this neuroanatomy is that the description of a fracture or dislocation resulting in a neurological injury at the T12-L1 vertebral motion segment tells us very little about the precise neurological structure that has been injured.

The neurological structures at the level of the thoracolumbar spine are critical for lower-extremity motor and sensory function as well as bowel, bladder, and sexual function. The lumbar sympathetic, sacral parasympathetic, and sacral somatic nerves originate within the conus medullaris and are carried within the nerve roots of the cauda equina. Although many of these lumbar roots descend over several vertebral segments within the thecal sac, the formal designation of the cauda equina begins below the termination of the conus medullaris. The cauda equina is an anatomical region where the only remnant of the spinal cord is the filum terminale and where the neurological structures include the lumbar and sacral nerve roots.

\section{Incidence of Conus Medullaris and Cauda Equina Syndromes}

McKinley et al. ${ }^{43}$ have reviewed SCI clinical syndromes in 839 patients admitted for inpatient rehabilita- tion. Although the series included traumatic and nontraumatic injuries, the incidences of CEI and CMI were 5.2 and $1.7 \%$, respectively. However, most of the CMIs were the result of trauma and $57 \%$ of these patients had ASIA Grade A or B function. Importantly, patients were categorized according to their clinical presentation; specifically their pattern of neurological injury and not their neuroanatomical level of injury based on imaging.

\section{Clinical Evaluation}

A thorough ATLS (advanced trauma life support) approach should be adhered to when evaluating a trauma patient with a spinal column injury. ${ }^{25}$ The neurological examination is critical for characterizing the type of clinical syndrome a patient has sustained and is a key factor in management decisions ${ }^{58}$ and prognostication.

Examination of a patient with an acute traumatic CMI may reveal variable lower-extremity weakness, absent lower-limb reflexes, and saddle anesthesia. Preservation or early return of the BCR and anal reflex (usually reestablished 48 hours after SCI) are more commonly observed in patients with SCIs, whereas they are typically abolished with either CMI or CEI. Cauda equina injuries are pure lower motor neuron injuries. Their presentation may include absent deep tendon reflexes and BCR, a flaccid urinary bladder, and reduced lower-extremity muscle tone. ${ }^{22}$ Asymmetrical lower-extremity weakness would favor a diagnosis of CEI when the clinical syndrome and advanced imaging studies render the classification of the presenting neurological syndrome more difficult. Such might be the case in an L-1 or L-2 burst fracture when the conus is not adequately visualized on MR imaging. This differentiation has relevance because, according to a strict interpretation of the ASIA classification, ${ }^{20,40}$ CEIs are not given an ASIA scale score. The BCR, delayed plantar reflex, and lower-limb deep tendon reflexes are variably used to describe the presence or absence of spinal shock, but they have a diminished clinical role in the setting of CMI and CEI because they may never return (Table 1).

Various authors have attempted to correlate the neural axis level of injury with the severity of the initial neurological deficit. Gertzbein and associates ${ }^{24}$ have stated that a positive relationship existed between an injury level and neurologic deficits, with more severe neurological injuries more likely to occur at the cord level. Using measurements of canal stenosis at the epiconus, conus medullaris, and cauda equina, in patients with and without neurological deficits, Hashimoto and coworkers ${ }^{27}$ and Kim and colleagues ${ }^{35}$ have demonstrated that a smaller degree of canal compromise results in greater neurological dysfunction at the epiconus level than the conus medullaris and cauda equina. Meves and Avanzi ${ }^{45}$ have retrospectively analyzed data obtained in 184 patients and found that the degree of canal encroachment in thoracolumbar burst fractures was associated with the severity of the neurological deficit. These results reinforce the concept that the initial neurological deficit is influenced by both the magnitude of the traumatic neural impingement and by the anatomical and neurological level of injury. 
Factors affecting outcome after traumatic spinal injuries

TABLE 1: Summary of complete epiconus injuries, CMls, and CEls*

\begin{tabular}{|c|c|c|c|c|}
\hline $\begin{array}{l}\text { Neurological } \\
\text { Syndrome }\end{array}$ & $\begin{array}{l}\text { Neurological } \\
\text { Level of Injury }\end{array}$ & Clinical Examination & Electrophysiological Testing & $\begin{array}{l}\text { Bowel, Bladder, \& } \\
\text { Sexual Function }\end{array}$ \\
\hline epiconus & above T-12 & $\begin{array}{l}\text { conus segments intact, } \\
\text { UMN syndrome, } \\
\text { BCR \& AR preserved; } \\
\text { muscle tone increased }\end{array}$ & $\begin{array}{l}\text { segmental recordings intact } \\
\text { (EMG, NCS, F-wave, H-reflex); } \\
\text { SSEP: tibial \& pudendal } \\
\text { abolished }\end{array}$ & $\begin{array}{l}\text { bladder-bowel dysfunction, } \\
\text { UMN type (bladder-detrusor- } \\
\text { sphincter dyssynergia); } \\
\text { sexual dysfunction (in men } \\
\text { preserved reflexogenic erec- } \\
\text { tions, loss of psychogenic } \\
\text { erection) }\end{array}$ \\
\hline $\begin{array}{l}\text { conus } \\
\text { medullaris }\end{array}$ & $\begin{array}{l}\text { T12-L1 to } \\
\text { S4-5 }\end{array}$ & $\begin{array}{l}\text { complete damage of conus } \\
\text { medullaris; } \\
\text { LMN syndrome; } \\
\text { all reflexes (sacral \& limbs } \\
\text { abolished); } \\
\text { muscle tone flaccid w/ atro- } \\
\text { phic changes }\end{array}$ & $\begin{array}{l}\text { NCS: tibial \& peroneal nerves } \\
\text { show axonal damage (<10 } \\
\text { days); } \\
\text { EMG: limb \& sacral myotomes } \\
\text { show severe denervation; } \\
\text { SSEP: tibial \& pudendal } \\
\text { abolished }\end{array}$ & $\begin{array}{l}\text { bladder-bowel dysfunction, } \\
\text { LMN type (atonic bladder \& } \\
\text { flaccid anal sphincter); } \\
\text { sexual dysfunction (in men } \\
\text { loss of reflexogenic erec- } \\
\text { tion, psychogenic erection } \\
\text { preserved) }\end{array}$ \\
\hline cauda equina & below L-2 & $\begin{array}{l}\text { LMN syndrome; } \\
\text { motor: variable L/E weakness, } \\
\text { diminished tone (asymmetry } \\
\text { favors CEI over CMI); } \\
\text { sensory: variable sensory } \\
\text { deficit; } \\
\text { reflexes: dependent on level } \\
\text { of injury }\end{array}$ & $\begin{array}{l}\text { NCS: tibial (L5-S1) \& per- } \\
\text { oneal (L4-5 dependent on } \\
\text { level of injury); } \\
\text { EMG: normal proximal limb, } \\
\text { denervation distal limb \& } \\
\text { sacral; } \\
\text { SSEP: pudendal affected, } \\
\text { tibial may be preserved }\end{array}$ & $\begin{array}{l}\text { bladder-bowel dysfunction, } \\
\text { LMN type (atonic bladder \& } \\
\text { flaccid anal sphincter); } \\
\text { sexual dysfunction (in men } \\
\text { loss of reflexogenic erec- } \\
\text { tion, psychogenic erection } \\
\text { preserved) }\end{array}$ \\
\hline
\end{tabular}

* Reflects a summary of complete lesions; more variation will be observed for incomplete lesions. Abbreviations: AR = adductor reflex; L/E = lower extremity; LMN = lower motor neuron; NCS = nerve conduction study; UMN = upper motor neuron; SSEP = somatosensory evoked potential.

\section{Imaging Assessment}

Although plain radiographs provide useful information, particularly when assessing the effects of gravity on spinal alignment in a patient without a neurological deficit and questionable stability, their utility in the evaluation of an acute neurological deficit at the thoracolumbar spine is exceeded by advanced imaging modalities. Sagittal and coronal CT reconstructions are crucial for characterizing the osseous injury as well as the resultant osseous canal compromise. In the setting of a neurological deficit attributable to a traumatic thoracolumbar injury, MR imaging is almost always advisable. An MR imaging study may not be appropriate due to medical instability, patient size, or other contraindications related to metallic implants. The value of MR imaging includes the assessment of spinal cord signal change, evaluation of the posterior ligamentous complex, and nonosseous compression such as epidural hematomas. The integrity of the posterior ligamentous complex is an important consideration in the management of thoracolumbar burst fractures, and it is best evaluated with STIR or fatsuppressed T2-weighted sequences on MR imaging (Fig. 2). ${ }^{36,58}$ Magnetic resonance imaging may also be of value in anticipating treatment complexities such as identifying the presence and location of disc or bone fragments in the spinal canal, anticipating the location of maximal spinal cord compression, and planning surgical approaches (Fig.
3). The extent of abnormal signal change in the spinal cord may have prognostic significance, as would a physical cord transection.

The most common spinal column injuries resulting in CMI or CEI are burst fractures and fracture dislocations. Flexion-distraction injuries may also lead to neurological deficits at these levels, although they are less common and have less risk of an associated neurological lesion. ${ }^{18,23,38}$

Combining the assessment of spinal stability, neurological status, and unique patient factors, the surgeon is now able to develop an appropriate management plan.

\section{Management}

\section{Factors Affecting Neurological Outcome}

Canal Encroachment. In a small retrospective study, Herndon and Galloway ${ }^{28}$ found that there was no difference in neural recovery based on the final spinal canal area or spinal level of injury (T11-L2). No attempt was made to separate injuries according to the neural axis level. In their studies, Dai and colleages ${ }^{13}$ and Mohanty and Venkatram ${ }^{46}$ observed no association between initial canal encroachment and neurological recovery.

Operative and Nonoperative Treatment. In the setting 


\section{S. P. Kingwell, A. Kurt, and M. F. Dvorak}

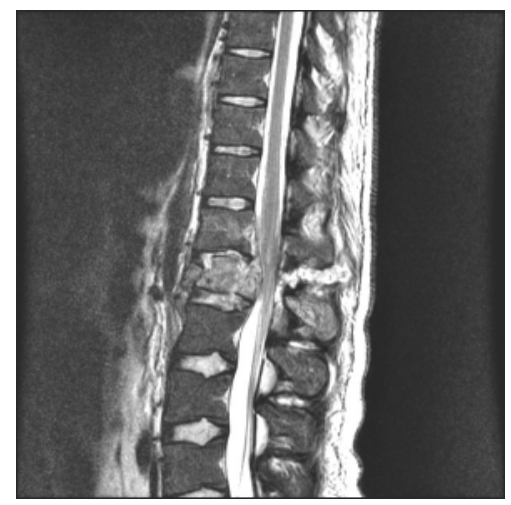

FIG. 2. Sagittal T2-weighted MR image demonstrating an L-1 burst fracture with disruption of the posterior ligamentous complex and maximum compression at the level of the conus medullaris.

of CMI and CEI secondary to spinal column trauma, the treating surgeon must decide whether surgical treatment is indicated and, if so, what the surgical plan should entail. Ideally, the analysis should be evidence based and consider the balance of harms, benefits, and costs of a proposed intervention..$^{53}$ Treatment options include bed rest, orthoses, and various surgical approaches, construct lengths, and instrumentation alternatives. ${ }^{1-3,5,8,11,12,19,21,31-33,41,42,44,49,52,55}$ Prior to deciding on the precise option for definitive treatment, the surgeon must also determine the best location in which the care will take place. This depends on the local organization of trauma and spinal care systems, but there has been a definite move toward providing subspecialty care in dedicated spine and/or trauma units. It is hoped that the provision of protocol-directed care in these specialized centers will improve outcomes. This may be particularly relevant in the case of traumatic CMI or CEI in cases in which the patient will likely benefit from early expert management related to bowel and bladder function. Depending on the injury type, hospital resources, surgeon training, and availability of rehabilitation, management may include a referral to a more specialized center. Even at a center providing early stabilization and triage, the physician must ensure appropriate immobilization of the patient while minimizing time on transport devices, restoration of physiological hemodynamics and oxygenation, bladder drainage, and prevention of decubitus ulcers.

A review of published literature involving traumarelated neurological deficits affecting the thoracolumbar and lumbar spine reveals generally low-quality retrospective studies of heterogeneous patients and treatment approaches. Results specifically cited as relating to CMI or CEI may not be precisely applicable to these injuries because these syndromes are typically inferred based on the spinal level of injury or the neurological presentation.

Boerger and colleagues ${ }^{4}$ have conducted a systematic review on the effectiveness of surgical decompression for thoracolumbar burst fractures in patients with a neurological deficit. Overall, a weak trend toward improved recovery in the nonsurgical group was reported in the context of heterogeneous surgical techniques. Patients with incomplete neurological deficits fared better after undergoing surgical stabilization and decompression. This review, which is supported by findings in other stud-

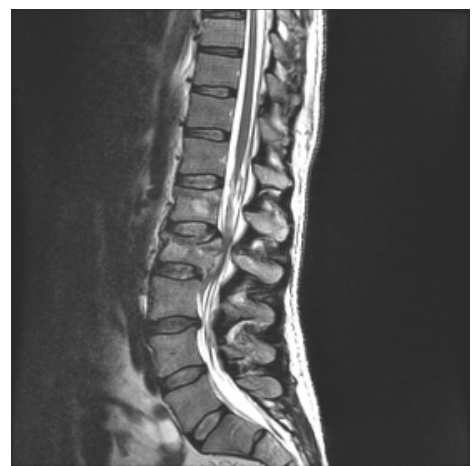

FIG. 3. Sagittal T2-weighted MR image demonstrating an L-2 burst fracture and compression of the cauda equina. Note the tip of the conus medullaris at the T12-L1 disc space.

ies, continues to underscore that nonsurgical treatment is

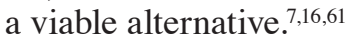

Dall and Stauffer ${ }^{14}$ have analyzed a small group of patients with T-12 and L-1 burst fractures and an incomplete neurological deficit, which they considered a "conus lesion." Only 6 of 14 patients had a functioning bladder initially, whereas 11 of 14 had normal bladder function at 1 year. Initial bladder function and recovery did not correlate with canal compromise, fracture pattern, or treatment (operative or nonoperative). There was no correlation between neurological recovery and nonoperative or surgical treatment in a study by Dendrinos et al..$^{17}$

Kim and coworkers ${ }^{35}$ reviewed data in patients with 148 consecutive burst fractures, 71 of which were associated with a neurological deficit. A complete neurological injury was present in 23 patients and an incomplete neurological injury was present in 48 . The neurological injury was defined as epiconus, conus medullaris, or cauda equina based on the spinal level, and the treatment varied between nonsurgical or anterior and posterior surgery. Canal compromise, the extent of decompression, and treatment technique were not found to be correlated with neurological recovery.

Lifeso and coworkers ${ }^{37}$ have identified a subgroup of patients with an adequate decompression and resultant improved neurological recovery, but they detected no difference in terms of overall neurological outcome between operative and nonoperative treatment groups.

Other authors have suggested that patients with neurological deficits secondary to thoracolumbar and lumbar spinal injuries may benefit from surgical treatment in terms of shorter hospital stays, which often lead to more timely active rehabilitation. , $7,16,30^{-1}$

As a result of the population-based study by Daniels et al., ${ }^{15}$ it would appear that patients with traumatic CMI, CEI, and SCI are frequently treated nonsurgically. Only $61.4 \%$ of patients with a thoracolumbar fracture and a neurological injury underwent surgery. The percentage is only slightly greater in the highest-volume centers. The conclusions drawn by Daniels et al. were based on a review of treatment codes and may be inherently flawed due to the potential inaccuracies in this type of administrative data.

In our opinion, the specific expertise necessary to provide safe, effective nonoperative care to patients with 
a SCI may be diminishing, particularly in North America and Europe. Contributing factors include external pressure to decrease length of stay in the acute hospital setting, better instrumentation techniques, and the trend to considering neurological status as a critical component in surgical decision making. ${ }^{58}$ Furthermore, the hospital resources necessary to treat patients nonsurgically-specifically the availability of specialized beds, the availability of staff skilled in repositioning a patient with an unstable spine every 2 hours, and the willingness to delay participation in active rehabilitation-are all in short supply in most modern-day health care systems.

Although nonsurgical care of traumatic CMI and CEI will likely result in some degree of neurological improvement, the vast majority of these injuries should be treated with surgical stabilization and, when necessary, a concomitant decompression. Not only is this likely to reduce the duration of hospital stay and facilitate nursing and rehabilitation, but it is clearly safe from a neurological perspective and may optimize neurological recovery.

\section{Surgical Approach/Timing}

McAfee et al..$^{41}$ have evaluated 48 patients with thoracolumbar fractures and incomplete neurological deficits who underwent anterior decompression. Sixteen patients had pure CEI, 2 had CMI, and 30 had both. Only 12 of the 32 patients with CMI recovered normal bowel and bladder function. Furthermore, neural recovery was not associated with the timing of decompression. A minimum improvement of 1 motor grade was found in all patients with a CEI. The efficacy of anterior decompression outside of the early treatment period has been corroborated by others, specifically bladder improvement for injuries at T12-L1.39,57

Bradford and McBride ${ }^{8}$ have retrospectively examined data obtained in 59 patients with thoracic and lumbar fractures. Thirty-three had a conus medullaris lesion and 17 had a CEI based on initial clinical examination and injury level (L-1 and L-2). Neurological improvement was not different overall between conus lesions treated anteriorly or posteriorly, but there were highly significant rates of bowel and bladder recovery between the posteriorly $(11.7 \%)$ and anteriorly $(70 \%)$ treated groups. Importantly, a statistically significant difference was seen in the quality of decompression for the anterior group, and many patients in the posterior group underwent decompression alone.

$\mathrm{Hu}$ et al. ${ }^{29}$ have evaluated 69 patients with lumbar fractures and incomplete neurological deficits at an average of 19 months postoperatively. When examined as a group, patients with CMI (L-1) or CEI (L-2 or below) had statistically greater motor improvement, whether the decompression was anterior or posterior, compared with patients who underwent posterior fusion alone (7.7 vs 4.6).

Rahimi-Movaghar and colleagues ${ }^{47}$ have retrospectively examined data acquired in 24 patients with traumatic CMI treated with posterior decompression and fusion and followed for 6 months. Patients with a neurological deficit and a T-12 or L-1 spinal column injury were inferred to have a CMI, although it is not clear whether the patient's conus medullaris was visualized on MR im- aging. Sixty-six percent of patients initially had a complete neurological injury. Some degree of neurological recovery was seen in $41.6 \%$, with an average Frankel score improvement of 1.5 and motor score improvement of 15 points. Bladder function improved in $63.6 \%$ and nerve root recovery occurred in $83 \%$ of the patients. Despite the promising attempt to analyze a homogeneous group, the value of the results are diminished by the lack of a control group, the small sample size, and no accounting for a potential variation in the conus medullaris location. Nonetheless, it would appear that posterior surgery alone is safe and acceptable in patients with CMI secondary to spinal column trauma.

Boriani and coworkers ${ }^{5}$ have reported on a cohort of 101 patients and differentiated among SCI, CEI, and CMI. They noted that $79 \%$ of 19 patients with CMI or CEI experienced partial or complete resolution of their neurological symptoms. The surgical approach was generally early posterior decompression and stabilization, and delayed anterior vertebrectomy was an option depending on stability.

Kaneda and associates ${ }^{31}$ have retrospectively reviewed data obtained in 150 consecutive patients with a thoracolumbar burst fracture and a neurological deficit who underwent anterior decompression and fusion; all patients were treated at a single center. Categorization of the neurological syndrome was based on clinical assessment: 13 patients had a pure CMI, 33 patients had a mixed CMI/CEI, and 69 patients had a pure CEI or nerve root injury. The difference between pre- and postoperative motor scores was greater in spinal cord-injured patients than in those with CEI, but the final motor score was higher in patients with CEI. There was no association between timing of surgery (earlier or later than 1 month) and the degree of neurological recovery, and nearly $75 \%$ of patients had complete neurological recovery. These dramatic neurological improvements have not been replicated in other studies. Only $5 \%$ of the patients had no recovery of neurological function at final follow-up. Complete bladder recovery was similar in the CMI and CEI groups and was present in $79 \%$ but only $59 \%$ for the epiconus group. McKinley et al. ${ }^{43}$ have also found parity between CMI and CEI in terms of final scores of sphincter control Functional Independence Measure and total motor Functional Independence Measure.

Clohisy and coworkers ${ }^{12}$ have examined the rate of neurological recovery in 20 patients based on the timing of surgery (within 48 hours compared with an average of 61 days) in cases of thoracolumbar fractures treated with anterior decompression and stabilization. Initially $75 \%$ of the patients with CMI exhibited profound bowel, bladder, and perianal sensory deficits. After early decompression, $44 \%$ of the patients had complete return of voluntary bowel and bladder function, whereas no patient who underwent late decompression had complete return of these functions. This result was not statistically significant and, based on the data presented, there is no reliable way to quantify and compare the 2 groups pre- or postoperatively. Motor improvement was significantly better in the group in which early decompression was performed. Unfortunately this study was underpowered, and the only 
conclusions that can be drawn from it are that early surgery is likely safe to perform and does not appear to be associated with a profound risk of neurological deterioration.

In a systematic review, Rutges et al. ${ }^{50}$ have examined the timing of surgery in thoracic and lumbar fractures, and they concluded that early fixation improved clinical outcome in terms of complications and duration of hospital stay but that it had an unclear effect on neurological outcome. Studies were not limited to the thoracolumbar and lumbar spine, however. Included in the aforementioned systematic review was the study by Rath et al. ${ }^{48}$ in which the authors reviewed 42 patients with a neurological deficit secondary to a thoracic or lumbar fracture; Rath et al. found that spinal level of injury did not influence neurological recovery.

Although no definite conclusions can be made with respect to the timing of decompression for traumatic CEI and CMI, the importance of early surgical intervention in the setting of atraumatic CEI is convincing. ${ }^{56}$ Still, the many pathophysiological differences between the atraumatic and traumatic setting, such as the energy imparted to the neural structures, repeated insults, and secondary damage, as well as vascular insufficiency should lead to caution when extrapolating results.

\section{Gunshot Wounds}

In a prospective, multicenter study, Waters and Adkins $^{60}$ have observed that motor recovery was statistically greater in patients who underwent bullet removal for retained fragments when the lesion was between T-12 and L-4. This trend persisted when the groups were analyzed according to the completeness of the neurological injury. Bullet removal did not affect motor recovery in the thoracic spine: complete injuries had poor motor recovery and incomplete injuries improved irrespective of the treatment.

\section{Rehabilitation Interventions}

Early rehabilitative interventions for CMI and CEI are comparatively more important for overall patient outcomes than neurological outcomes. The involvement of a rehabilitation specialist at an early stage allows for continuity of care during the acute and rehabilitative phases. Early rehabilitative interventions include measures aimed at avoiding secondary complications. Patients with CMIs and CEIs should receive pharmacological thromboprophylaxis, and this treatment will continue into the rehabilitative phase. Depending on the duration of the stay in the acute hospital and the expertise of the hospital staff, the rehabilitation specialist may lead the discussion and initiate changes in bladder and bowel management. Patients and families will often have significant concerns regarding future bowel, bladder, and sexual function in addition to ambulatory potential. With CEI and CMI, ambulatory potential is often promising and the focus of critical education and counseling may be on bowel, bladder, and sexual function. Importantly, the rehabilitation specialist is continually assessing patients for their readiness to par- ticipate in an active SCI rehabilitation program. Typically this includes resolution of acute medical issues, cognitive understanding and motivation, and control of nociceptive and neuropathic pain.

\section{Summary of Factors Affecting Neurological Outcome}

Overall, there are many compelling arguments to favor a particular management approach in the treatment of traumatic CMI and CEI. From the perspective of neurological recovery, however, it is difficult to tease out critical factors that will influence recovery from the existing literature. The most important factor is likely the severity of the initial neurological deficit, and incomplete injuries are likely to improve in most circumstances. Initial spinal canal encroachment is not related to neurological outcome. Generally, based on what we found in the available literature, the selection of operative or nonoperative treatment and the timing of surgery do not appear to have a significant impact on neurological recovery. It should be noted that the timing of surgery reported is extremely variable. Many practitioners who are advocates of early surgery would consider surgery after 6-8 hours as delayed and yet early surgery is frequently categorized as that occurring before 48 hours. Anterior and posterior surgery result in similar neurological outcomes, although anterior decompression may lead to greater recovery of bladder function. Removal of bullet fragments in the setting of CMI and CEI is associated with improved neurological outcome (Table 2).

\section{Management of Bladder/Sexual Function}

Epiconus injuries result in an upper motor neuron syndrome of bladder dysfunction, whereas CEIs result in a lower motor neuron presentation. Injuries located within the conus medullaris will lead to a more variable degree of bladder dysfunction depending on the neuroanatomical structures involved but are typically lower motor neuron. Lower motor neuron syndrome is characterized by injury to the S2-4 anterior horn cells or the corresponding axons, and results in weak or flaccid detrusor activity. ${ }^{9}$ The resultant atonic and flaccid bladder leads to urinary retention and overflow incontinence. Clinically, the BCR is abolished and the anal sphincter tone is reduced. Treatment consists of clean intermittent catheterization to ensure complete bladder emptying. Management goals include avoidance of bladder overdistension and retrograde urine flow, which may lead to pyelonephritis and secondary renal failure. In upper motor neuron syndrome the sacral micturition center and sacral reflex arcs continue to respond, although they are deprived of suprasacral control (brainstem and cortical micturition centers). This syndrome may lead to detrusor-sphincter dyssynergia with detrusor hyperreflexia. The latter is defined by increased pressure within the bladder and the potential risk of retrograde urine flow. Treatment is based on anticholinergic medication, or the application of botulinum toxin to the bladder wall in resistant cases, to reduce detrusor hyperreflexia and enable urine evacuation by clean intermit- 
Factors affecting outcome after traumatic spinal injuries

TABLE 2: Factors affecting neurological outcome in traumatic CMls and CEls

\begin{tabular}{|c|c|c|}
\hline Factor & Conus Medullaris & Cauda Equina \\
\hline initial canal encroachment & $\begin{array}{l}\text { greater canal encroachment associated } \\
\text { w/ severity of neurological deficit but } \\
\text { unrelated to recovery }\end{array}$ & $\begin{array}{l}\text { greater canal encroachment associated w/ } \\
\text { severity of neurological deficit }\end{array}$ \\
\hline nonop vs op management & no difference in neurological recovery & no difference in neurological recovery \\
\hline anterior vs posterior stabilization & no difference in motor recovery & no difference in motor recovery \\
\hline decompression \& fusion vs fusion & $\begin{array}{l}\text { decompression associated w/ greater } \\
\text { neurological recovery; anterior decom- } \\
\text { pression may result in greater bladder } \\
\text { recovery }\end{array}$ & $\begin{array}{l}\text { decompression associated } \mathrm{w} / \text { greater } \\
\text { neurological recovery }\end{array}$ \\
\hline $\begin{array}{l}\text { early ( }<48 \mathrm{hrs} \text { ) vs late op } \\
\text { removal of retained bullet fragments }\end{array}$ & $\begin{array}{l}\text { no difference in neurological recovery } \\
\text { improved motor recovery }\end{array}$ & $\begin{array}{l}\text { no difference in neurological recovery } \\
\text { improved motor recovery }\end{array}$ \\
\hline
\end{tabular}

tent catheterization. The use of condom catheters in male patients should be monitored by regular urodynamic examinations to avoid the development of a hyperreflexive bladder and to prevent late complications.

Chuang et al. ${ }^{10}$ have attempted to characterize neurourological abnormalities based on the neural axis level of injury. Importantly, they used MR imaging to identify the true conus medullaris level in their attempt to investigate voiding dysfunction following thoracolumbar injuries. They found that the conus was most commonly at the L-1 level, but its range included T12-L3. Through EMG and urodynamic testing, they found that neurourological abnormalities were less predictable for conus medullaris and supra-conus medullaris lesions than for cauda equina injuries.

With respect to sexual function, men with a lower motor neuron lesion will have more difficulty achieving a reflexive erection from tactile stimulation owing to the disruption of a parasympathetically mediated reflex arc (S2-4). Psychogenic erections mediated sympathetically from T10-12 may still occur in cases of lower motor neuron lesions, whereas they are usually not sufficient to allow for sexual intercourse. In cases of upper motor neuron lesions, male patients have preserved reflexive erections while the psychogenic erection is abolished. ${ }^{9}$ The pharmacological treatment of erectile dysfunction depends on the level and extent of the SCI. Fertility issues, for female and male patients, should be specifically addressed by urologists and gynecologists with a specific interest in SCI because most patients will retain the ability to have children.

\section{Conclusions}

Despite the numerous publications on thoracolumbar and lumbar fractures, conclusions regarding CMI and $\mathrm{CEI}$ have been inferred because few studies account for the variable location of the conus medullaris within the spinal canal. Not unexpectedly, a greater degree of initial canal compromise is apparent in patients with a CMI or CEI than in those with a spinal cord level injury. There is a paucity of robust evidence favoring surgical decompression and stabilization of CEI and CMI over nonoperative treatment in terms of neurological outcome. However, like SCIs, complete CMIs and CEIs are much less likely to improve than incomplete injuries. Furthermore, surgical decompression for incomplete thoracolumbar injuries has become common practice and is supported by poorquality evidence in the literature. Nonsurgical treatment results in neurological improvement as well; however, the comparative efficacy or effectiveness of surgery and nonsurgical treatment cannot be assessed based on the available evidence specific to CMI or CEI.

Regardless of the potential influence of surgical treatment on neurological improvement, surgery may be preferred due to shorter hospital stays, earlier rehabilitation, availability of equipment and expert nursing care, and patient preference. When surgical treatment is selected, combined posterior decompression and stabilization appears to offer equivalent neurological outcomes in both CMI and CEI, with the benefits of surgeon familiarity and reduced morbidity. Anterior decompression may offer potential benefits in terms of bladder recovery, particularly in the delayed setting. Based the available evidence, the timing of surgery for traumatic CMI or CEI does not affect neurological recovery. Certainly, there does not appear to be any evidence of a deleterious effect from early surgical stabilization and/or decompression. Overall, CEI and CMI have similar outcomes that include ambulatory motor function and a variable persistence of bowel, bladder, and potentially sexual dysfunction.

\section{Disclaimer}

The authors report no conflict of interest concerning the materials or methods used in this study or the findings specified in this paper.

\section{References}

1. Aebi M, Mohler J, Zach G, Morscher E: Analysis of 75 operated thoracolumbar fractures and fracture dislocations with and without neurological deficit. Arch Orthop Trauma Surg 105:100-112, 1986

2. Been HD, Bouma GJ: Comparison of two types of surgery for thoraco-lumbar burst fractures: combined anterior and posterior stabilisation vs. posterior instrumentation only. Acta Neurochir (Wien) 141:349-357, 1999 
3. Benson DR, Burkus JK, Montesano PX, Sutherland TB, McLain RF: Unstable thoracolumbar and lumbar burst fractures treated with the AO fixateur interne. J Spinal Disord 5:335-343, 1992

4. Boerger TO, Limb D, Dickson RA: Does 'canal clearance' affect neurological outcome after thoracolumbar burst fractures? J Bone Joint Surg Br 82:629-635, 2000

5. Boriani S, Palmisani M, Donati U, Tella G, de Lure F, Bandiera $S$, et al: The treatment of thoracic and lumbar spine fractures: a study of 123 cases treated surgically in 101 patients. Chir Organi Mov 85:137-149, 2000

6. Braakman R: The value of more aggressive management in traumatic paraplegia. Neurosurg Rev 9:141-147, 1986

7. Braakman R, Fontijne WP, Zeegers R, Steenback JR, Tanghe HL: Neurological deficit in injuries of the thoracic and lumbar spine. A consecutive series of 70 patients. Acta Neurochir (Wien) 111:11-17, 1991

8. Bradford DS, McBride GG: Surgical management of thoracolumbar spine fractures with incomplete neurologic deficits. Clin Orthop Relat Res 218:201-216, 1987

9. Burns AS, Rivas DA, Ditunno JF: The management of neurogenic bladder and sexual dysfunction after spinal cord injury. Spine 26:S129-S136, 2001

10. Chuang TY, Cheng H, Chan RC, Chiang SC, Guo WY: Neurourologic findings in patients with traumatic thoracolumbar vertebra junction lesions. Arch Phys Med Rehabil 82:375379, 2001

11. Cigliano A, Scarano E, De Falco R, Profeta G: The posterolateral approach in the treatment of post-traumatic canalar stenosis of the thoraco-lumbar spine. J Neurosurg Sci 41:387-393, 1997

12. Clohisy JC, Akbarnia BA, Bucholz RD, Burkus JK, Backer RJ: Neurologic recovery associated with anterior decompression of spine fractures at the thoracolumbar junction (T12-L1). Spine 17:S325-S330, 1992

13. Dai LY, Wang XY, Jiang LS: Neurologic recovery from thoracolumbar burst fractures: is it predicted by the amount of initial canal encroachment and kyphotic deformity? Surg Neurol 67:232-237, 2007

14. Dall BE, Stauffer ES: Neurologic injury and recovery patterns in burst fractures at the T12 or L1 motion segment. Clin Orthop Relat Res 233:171-176, 1988

15. Daniels AH, Arthur M, Hart RA: Variability in rates of arthrodesis for patients with thoracolumbar spine fractures with and without associated neurologic injury. Spine 32:23342338, 2007

16. Davies WE, Morris JH, Hill V: An analysis of conservative (non-surgical) management of thoracolumbar fractures and fracture-dislocations with neural damage. J Bone Joint Surg Am 62:1324-1328, 1980

17. Dendrinos GK, Halikias JG, Krallis PN, Asimakopoulos A: Factors influencing neurological recovery in burst thoracolumbar fractures. Acta Orthop Belg 61:226-234, 1995

18. Denis F: The three column spine and its significance in the classification of acute thoracolumbar spinal injuries. Spine 8:817-831, 1983

19. Dimar JR II, Wilde PH, Glassman SD, Puno RM, Johnson JR: Thoracolumbar burst fractures treated with combined anterior and posterior surgery. Am J Orthop 25:159-165, 1996

20. Ditunno JF Jr, Young W, Donovan WH, Creasey G: The international standards booklet for neurological and functional classification of spinal cord injury. American Spinal Injury Association. Paraplegia 32:70-80, 1994

21. Dvorak MF, Kwon BK, Fisher CG, Eiserloh HL III, Boyd M, Wing PC: Effectiveness of titanium mesh cylindrical cages in anterior column reconstruction after thoracic and lumbar vertebral body resection. Spine 28:902-908, 2003

22. Ertekin C, Reel F, Mutlu R, Kerkuklu I: Bulbocavernosus re- flex in patients with conus medullaris and cauda equina lesions. J Neurol Sci 41:175-181, 1979

23. Gertzbein SD: Scoliosis Research Society. Multicenter spine fracture study. Spine 17:528-540, 1992

24. Gertzbein SD, Court-Brown CM, Marks P, Martin C, Fazl M, Schwartz M, et al: The neurological outcome following surgery for spinal fractures. Spine 13:641-644, 1988

25. Harris MB, Sethi RK: The initial assessment and management of the multiple-trauma patient with an associated spine injury. Spine 31:S9-S15, 2006

26. Harrop JS, Hunt GE Jr, Vaccaro AR: Conus medullaris and cauda equina syndrome as a result of traumatic injuries: management principles. Neurosurg Focus 16(6):e4, 2004

27. Hashimoto T, Kaneda K, Abumi K: Relationship between traumatic spinal canal stenosis and neurologic deficits in thoracolumbar burst fractures. Spine 13:1268-1272, 1988

28. Herndon WA, Galloway D: Neurologic return versus crosssectional canal area in incomplete thoracolumbar spinal cord injuries. J Trauma 28:680-683, 1988

29. Hu SS, Capen DA, Rimoldi RL, Zigler JE: The effect of surgical decompression on neurologic outcome after lumbar fractures. Clin Orthop Relat Res 288:166-173, 1993

30. Jodoin A, Dupuis P, Fraser M, Beaumont P: Unstable fractures of the thoracolumbar spine: a 10-year experience at Sacre-Coeur Hospital. J Trauma 25:197-202, 1985

31. Kaneda K, Taneichi H, Abumi K, Hashimoto T, Satoh S, Fujiya M: Anterior decompression and stabilization with the Kaneda device for thoracolumbar burst fractures associated with neurological deficits. J Bone Joint Surg Am 79:69-83, 1997

32. Katonis PG, Kontakis GM, Loupasis GA, Aligizakis AC, Christoforakis, JI, Velivassakis: Treatment of unstable thoracolumbar and lumbar spine injuries using Cotrel-Dubousset instrumentation. Spine 24:2352-2357, 1999

33. Kaya RA, Aydin Y: Modified transpedicular approach for the surgical treatment of severe thoracolumbar or lumbar burst fractures. Spine J 4:208-217, 2004

34. Kesler H, Dias MS, Kalapos P: Termination of the normal conus medullaris in children: a whole-spine magnetic resonance imaging study. Neurosurg Focus 23(2):E7, 2007

35. Kim NH, Lee HM, Chun IM: Neurologic injury and recovery in patients with burst fracture of the thoracolumbar spine. Spine 24:290-293, 1999

36. Lee HM, Kim HS, Kim DJ, Suk KS, Park JO, Kim NH: Reliability of magnetic resonance imaging in detecting posterior ligament complex injury in thoracolumbar spinal fractures. Spine 25:2079-2084, 2000

37. Lifeso RM, Arabie KM, Kadhi SK: Fractures of the thoracolumbar spine. Paraplegia 23:207-224, 1985

38. Magerl F, Aebi M, Gertzbein SD, Harms J, Nazarian S: A comprehensive classification of thoracic and lumbar injuries. Eur Spine J 3:184-201, 1994

39. Maiman DJ, Larson SJ, Benzel EC: Neurological improvement associated with late decompression of the thoracolumbar spinal cord. Neurosurgery 14:302-307, 1984

40. Maynard FM Jr, Bracken MB, Creasey G, Ditunno JF Jr, Donovan WH, Ducker TB, et al: International Standards for Neurological and Functional Classification of Spinal Cord Injury. American Spinal Injury Association. Spinal Cord 35:266-274, 1997

41. McAfee PC, Bohlman HH, Yuan HA: Anterior decompression of traumatic thoracolumbar fractures with incomplete neurological deficit using a retroperitoneal approach. J Bone Joint Surg Am 67:89-104, 1985

42. McDonough PW, Davis R, Tribus C, Zdeblick TA: The management of acute thoracolumbar burst fractures with anterior corpectomy and Z-plate fixation. Spine 29:1901-1908, 2004

43. McKinley W, Santos K, Meade M, Brooke K: Incidence and 


\section{Factors affecting outcome after traumatic spinal injuries}

outcomes of spinal cord injury clinical syndromes. J Spinal Cord Med 30:215-224, 2007

44. McLain RF, Burkus JK, Benson DR: Segmental instrumentation for thoracic and thoracolumbar fractures: prospective analysis of construct survival and five-year follow-up. Spine J 1:310-323, 2001

45. Meves R, Avanzi O: Correlation among canal compromise, neurologic deficit, and injury severity in thoracolumbar burst fractures. Spine 31:2137-2141, 2006

46. Mohanty SP, Venkatram N: Does neurological recovery in thoracolumbar and lumbar burst fractures depend on the extent of canal compromise? Spinal Cord 40:295-299, 2002

47. Rahimi-Movaghar V, Vaccaro AR, Mohammadi M: Efficacy of surgical decompression in regard to motor recovery in the setting of conus medullaris injury. J Spinal Cord Med 29:32-38, 2006

48. Rath SA, Kahamba JF, Kretschmer T, Neff U, Richter HP, Antoniadis G: Neurological recovery and its influencing factors in thoracic and lumbar spine fractures after surgical decompression and stabilization. Neurosurg Rev 28:44-52, 2005

49. Rechtine GR, Cahill D, Chrin AM: Treatment of thoracolumbar trauma: comparison of complications of operative versus nonoperative treatment. J Spinal Disord 12:406-409, 1999

50. Rutges JP, Oner FC, Leenen LP: Timing of thoracic and lumbar fracture fixation in spinal injuries: a systematic review of neurological and clinical outcome. Eur Spine J 16:579-587, 2007

51. Saifuddin A, Burnett SJ, White J: The variation of position of the conus medullaris in an adult population. A magnetic resonance imaging study. Spine 23:1452-1456, 1998

52. Sasso RC, Cotler HB: Posterior instrumentation and fusion for unstable fractures and fracture-dislocations of the thoracic and lumbar spine. A comparative study of three fixation devices in 70 patients. Spine 18:450-460, 1993

53. Schunemann HJ, Jaeschke R, Cook DJ, Bria WF, El-Solh AA, Ernst A, et al: An official ATS statement: grading the quality of evidence and strength of recommendations in ATS guidelines and recommendations. Am J Respir Crit Care Med 174:605-614, 2006
54. Soleiman J, Demaerel P, Rocher S, Maes F, Marchal G: Magnetic resonance imaging study of the level of termination of the conus medullaris and the thecal sac: influence of age and gender. Spine 30:1875-1880, 2005

55. Tezeren G, Kuru I: Posterior fixation of thoracolumbar burst fracture: short-segment pedicle fixation versus long-segment instrumentation. J Spinal Disord Tech 18:485-488, 2005

56. Todd NV: Cauda equina syndrome: the timing of surgery probably does influence outcome. Br J Neurosurg 19:301306, 2005

57. Transfeldt EE, White D, Bradford DS, Roche B: Delayed anterior decompression in patients with spinal cord and cauda equina injuries of the thoracolumbar spine. Spine 15:953957, 1990

58. Vaccaro AR, Lehman RA Jr, Hurlbert RJ, Anderson PA, Harris $\mathrm{M}$, Hedlund R, et al: A new classification of thoracolumbar injuries: the importance of injury morphology, the integrity of the posterior ligamentous complex, and neurologic status. Spine 30:2325-2333, 2005

59. Wall EJ, Cohen MS, Abitbol JJ, Garfin SR: Organization of intrathecal nerve roots at the level of the conus medullaris. J Bone Joint Surg Am 72:1495-1499, 1990

60. Waters RL, Adkins RH: The effects of removal of bullet fragments retained in the spinal canal. A collaborative study by the National Spinal Cord Injury Model Systems. Spine 16:934-939, 1991

61. Willen J, Dahllof AG, Nordwall A: Paraplegia in unstable thoracolumbar injuries. A study of conservative and operative treatment regarding neurological improvement and rehabilitation. Scand J Rehabil Med Suppl 9:195-205, 1983

Manuscript submitted July 15, 2008.

Accepted September 3, 2008.

Address correspondence to: Marcel F. Dvorak, M.D., F.R.C.S.C., D6 Heather Pavilion, 2733 Heather Street, Vancouver, British Columbia V5Z 3J5, Canada. email: marcel.dvorak@vch.ca. 